\title{
Correction to: Prognostic value of pulmonary oedema assessed by lung ultrasound in patient with acute heart failure
}

\author{
Feifei Yang ${ }^{1}\left(\mathbb{D} \cdot\right.$ Qiushuang Wang $^{1} \cdot$ Liwei Zhang $^{1} \cdot$ Yongjiang Ma ${ }^{1} \cdot$ Qiang Chen $^{1}$
}

Published online: 11 December 2020

(c) Springer Japan KK, part of Springer Nature 2020

Correction to: Heart and Vessels

https://doi.org/10.1007/s00380-020-01719-5

In the original publication of the article, the below article note was missed and included in this correction.

In addition, in Table 4, on the first column, the term "EVLWI" was included mistakenly. The correct Table 4 is provided below,

The original article was updated.

Publisher's Note Springer Nature remains neutral with regard to jurisdictional claims in published maps and institutional affiliations.

Feifei Yang and Qiushuang Wang are the first authors.

The original article can be found online at https://doi.org/10.1007/ s00380-020-01719-5.

Feifei Yang

cardiofeifei115@163.com

1 Department of Cardiology, Fourth Medical Center of Chinese, PLA General Hospital, Beijing 100048, China 
Table 4 Correlation between EVLWI and B-lines,

NT-proBNP, $E / e^{\prime}$

\begin{tabular}{lll}
\hline & $r$ & $P$ \\
\hline B-lines & 0.95 & $<0.001$ \\
NT-proBNP & 0.72 & $<0.001$ \\
E/e' & 0.62 & $<0.001$ \\
\hline
\end{tabular}

EVLWI extravascular lung water index, $E / e^{\prime}$ ratio of early diastolic mitral inflow velocity to early diastolic velocity of the mitral annulus 